\title{
Physical Activity and Trajectory of Cognitive Change in Older Persons: Mayo Clinic Study of Aging
}

\author{
Janina Krell-Roesch ${ }^{\mathrm{a}, \mathrm{b}}$, Jeremy A. Syrjanen ${ }^{\mathrm{a}}$, Jelena Bezold ${ }^{\mathrm{b}}$, Sandra Trautwein ${ }^{\mathrm{b}}$, \\ Bettina Barisch-Fritz ${ }^{\mathrm{b}}$, Klaus Boes ${ }^{\mathrm{b}}$, Alexander Woll ${ }^{\mathrm{b}}$, Erica Forzani ${ }^{\mathrm{c}}$, Walter K. Kremers ${ }^{\mathrm{a}}$, \\ Mary M. Machulda ${ }^{\mathrm{d}}$, Michelle M. Mielke ${ }^{\mathrm{a}, \mathrm{e}}$, David S. Knopman ${ }^{\mathrm{e}}$, Ronald C. Petersen ${ }^{\mathrm{a}, \mathrm{e}}$, \\ Maria Vassilaki ${ }^{\mathrm{a}}$ and Yonas E. Geda ${ }^{\mathrm{c}, \mathrm{f}, *}$ \\ ${ }^{a}$ Department of Health Sciences Research, Mayo Clinic, Rochester, MN, USA \\ ${ }^{\mathrm{b}}$ Institute of Sports and Sports Science, Karlsruhe Institute of Technology, Karlsruhe, Germany \\ ${ }^{\mathrm{c}}$ Biodesign Institute, Arizona State University, Tempe, AZ, USA \\ ${ }^{\mathrm{d}}$ Department of Psychiatry and Psychology, Mayo Clinic, Rochester, MN, USA \\ ${ }^{\mathrm{e}}$ Department of Neurology, Mayo Clinic, Rochester, MN, USA \\ ${ }^{\mathrm{f}}$ Department of Neurology, Barrow Neurological Institute, Phoenix, AZ, USA
}

Accepted 21 October 2020

\begin{abstract}
.
Background: Little is known about the association between physical activity (PA) and cognitive trajectories in older adults. Objective: To examine the association between PA and change in memory, language, attention, visuospatial skills, and global cognition, and a potential impact of sex or Apolipoprotein $\mathrm{E}(A P O E) \varepsilon 4$ status.

Methods: Longitudinal study derived from the population-based Mayo Clinic Study of Aging, including 2,060 cognitively unimpaired males and females aged $\geq 70$ years. Engagement in midlife (ages 50-65) and late-life (last year) PA was assessed using a questionnaire. Neuropsychological testing was done every 15 months (mean follow-up 5.8 years). We ran linear mixed-effect models to examine whether mid- or late-life PA at three intensities (mild, moderate, vigorous) was associated with cognitive z-scores.

Results: Light intensity midlife PA was associated with less decline in memory function compared to the no-PA reference group (time $\mathrm{x}$ light PA; estimate [standard error] 0.047 [0.016], $p=0.004$ ). Vigorous late-life PA was associated with less decline in language $(0.033$ [0.015], $p=0.030)$, attention $(0.032$ [0.017], $p=0.050)$, and global cognition (0.039 [0.016], $p=0.012)$. Females who were physically inactive in midlife experienced more pronounced cognitive decline than females physically active in midlife and males regardless of PA ( $p$-values for time interaction terms with midlife PA levels and sex were all $p<0.05$ for global cognition). APOE $\varepsilon 4$ carriership did not moderate the association between PA and cognition.

Conclusion: Engaging in PA, particularly of vigorous intensity in late-life, was associated with less pronounced decline in global and domain-specific cognition. This association may differ by sex.
\end{abstract}

Keywords: Cognitive trajectories, community-dwelling persons, late-life, midlife, physical activity

\footnotetext{
${ }^{*}$ Correspondence to: Yonas E. Geda, MD, MSc, Department of Neurology, Barrow Neurological Institute, 240W. Thomas Road, Phoenix, AZ 85013, USA. Tel.: +1 602406 8284; E-mail: Yonas.Geda@DignityHealth.org.
}

\section{INTRODUCTION}

Physical activity is a modifiable lifestyle factor that is associated with a decreased risk of mild cognitive impairment (MCI) or dementia [1-4], and may 
delay or slow cognitive decline in old age [5-10]. However, observational studies have reported conflicting findings [11]. Research has also shown that physical activity interventions may be associated with better performance across various cognitive domains, including in participants with MCI [12] whereas other trials could not establish an effect of a physical activity intervention on cognition in older adults with cognitive impairment [13].

Furthermore, the association between physical activity and cognitive function may differ by sex [14-16], and it has been proposed that females may experience greater cognitive benefits [17]. It has also been postulated that this association may be dependent on Apolipoprotein E (APOE) $\varepsilon 4$ carrier status $[1,18-21]$, which is a major genetic risk factor for late-onset Alzheimer's disease (AD) [22, 23]. However, it is not clear yet whether $A P O E \varepsilon 4$ carriers or non-carriers show greater cognitive benefits $[17,24]$. In addition, there is a scarcity of longitudinal observational studies investigating the association between physical activity and cognitive function in the elderly stratified by sex or $A P O E \& 4$ carrier status, while also particularly paying attention to the timing of physical activity engagement [17].

Therefore, the aim of the current study was to examine whether physical activity performed in midlife or late-life is associated with longitudinal change in memory function, language, visuospatial skills, attention, and global cognition. In addition, we also explored whether this association may differ by sex or $A P O E \& 4$ carrier status. We hypothesized that physical activity, particularly of moderate and vigorous intensity, would be associated with less decline in cognitive function over time, and that this association may differ by $A P O E \varepsilon 4$ carrier status and may be more pronounced in females.

\section{MATERIALS AND METHODS}

\section{Study sample and design}

This study was derived from the ongoing, population-based Mayo Clinic Study of Aging (MCSA) in Olmsted County, MN [25]. We included 2,060 cognitively unimpaired individuals, both sexes, aged $\geq 70$ years with available self-reported information on physical activity at baseline and serial cognitive data (i.e., at least one follow-up visit) from repeated neuropsychological testing. Data were collected between 2006-2018, with neuropsychological testing every 15 months on average. The MCSA protocols have been approved by the institutional review boards (IRB) of the Mayo Clinic and Olmsted Medical Center in Rochester, MN. All participants provided written informed consent.

\section{Neurocognitive evaluation}

Participants underwent a face-to-face evaluation including a neurological examination, a study coordinator visit, and neuropsychological testing [25]. Briefly, the neurological evaluation comprised a neurological history review, administration of the Short Test of Mental Status [26], and a neurological examination. The study coordinator visit included the Clinical Dementia Rating Scale (CDR) [27]. Neuropsychological testing was administered by a psychometrist in order to assess performance in four cognitive domains: memory (delayed recall trials from Auditory Verbal Learning Test [28], Wechsler Memory Scale-Revised [29], Logical Memory and Visual Reproduction subtests); language (Boston Naming Test [30], category fluency [31]); visuospatial skills (Wechsler Adult Intelligence Scale-Revised [32], Picture Completion and Block Design subtests); and attention/executive function (Trail-Making Test Part B [33], Wechsler Adult Intelligence ScaleRevised [32], Digit Symbol Substitution subtest). An expert consensus panel consisting of physicians, study coordinators, and neuropsychologists reviewed the results for each participant and determined whether a participant was cognitively unimpaired (CU) or had cognitive impairment. Individuals were classified as CU based on normative data developed in a different sample from this community [34-37]. MCI was determined based on the Mayo Clinic criteria for MCI $[38,39]$.

\section{Measurement of physical activity (predictor variable)}

Physical activity was measured at baseline using a self-reported questionnaire [40]. The questionnaire was derived from two validated instruments, the 1985 National Health Interview Survey and the Minnesota Heart Survey intensity codes [41, 42]. Participants provided information on intensity and frequency of physical activity at two time periods: 1) midlife, between the ages of 50 and 65 years; and 2) latelife, within 1 year prior to cognitive assessment. The questionnaire also distinguished between three intensity levels and provided examples of activities for each level: 1) light physical activity such as leisurely 
walking or dancing; 2) moderate physical activity such as hiking or swimming; and 3) vigorous physical activity such as jogging or playing tennis. Participants were asked to provide information about the frequency at which they carried out these activities: $\leq 1$ time per month, 2-3 times per month, 1-2 times per week, 3-4 times per week, 5-6 times per week, and daily. Previous research has shown that the questionnaire has moderate to good internal consistency [40].

\section{Neuropsychological test scores (outcome variable)}

Neuropsychological test scores were considered as outcome variables. This study used continuous measures of cognitive performance that were not agenormed, and calculated longitudinal z-scores relative to the baseline scores by converting individual test scores to z-scores. We then created domain-specific $\mathrm{z}$-scores by $\mathrm{z}$-scoring the average of the test-specific $\mathrm{z}$-scores, and also created a global z-score by $\mathrm{z}$ scoring the average of the domain-specific z-scores. The outcomes of interest for the linear mixed-effect model analyses were the longitudinal cognitive $\mathrm{z}$ scored measures of memory, language, attention, visuospatial skills, and global cognition.

\section{Assessment of confounding variables}

In addition to traditional confounders (i.e., age, sex, and education), the study also adjusted the analyses for medical comorbidity as assessed through the weighted Charlson Index [43], and $A P O E$ \& 4 genotype status which was determined using standard methods [44].

\section{Statistical analysis}

For statistical analyses, we created the following groupings for midlife and late-life physical activity separately: 1) non-active (reference group); 2) only light intensity physical activity; 3 ) moderate intensity physical activity (plus less intensity physical activity); 4) vigorous intensity physical activity (plus less intensity physical activity). Participants were considered active if they reported engaging in the respective physical activity intensity at least 1-2 times per week (i.e., they were considered inactive if they engaged 2-3 times per month or less). The analysis first compared baseline characteristics between groups using ANOVA (for continuous outcomes such as age; reported as mean and standard deviation, SD) and chi-square tests (for categorical outcomes such as sex; reported as number and percentage). Linear mixed-effect models were then calculated with random subject-specific intercepts and slopes for time to examine whether midlife or late-life physical activity were associated with the longitudinal cognitive end points. The first set of models included both midlife and late-life physical activity, level of physical activity (i.e., light, moderate and vigorous), time (in years from baseline), and the two-way interaction between these variables (time x physical activity). Associations between baseline physical activity (independent variable) and cognitive trajectories (dependent variable) were adjusted for baseline age, sex, education, medical comorbidity, APOE $\varepsilon 4$ genotype status, and whether or not the participant had previously taken the cognitive tests. In order to examine whether the association between physical activity and cognitive trajectories differs by sex or $A P O E \varepsilon 4$ genotype status, we also created models comprising two threeway interactions (time $\mathrm{x}$ physical activity $\mathrm{x}$ sex and time $\mathrm{x}$ physical activity $\mathrm{x} A P O E \varepsilon 4$, respectively). As three-way interactions are more difficult to interpret, we created plots for visual display of data. To create the plots, except for the variables of interest, we used the average values from baseline, i.e., all plots are created for the "average" person in our data set. This means that for age, we used the average age, for Charlson comorbidity index we used the average Charlson comorbidity index score, etc. Also, when looking at the interaction with midlife physical activity, for example, late life physical activity was set as moderate. In addition to the three-way interactions, we also created plots for the two-way interactions. Similarly, for the plots on midlife physical activity, we assumed moderate late-late physical activity and vice versa. The statistical analyses were conducted using the conventional two-tailed alpha level of 0.05 and performed with SAS 9.4 (SAS Institute, Inc., Cary, NC).

\section{RESULTS}

Of 2,060 cognitively unimpaired persons at baseline, 1,040 (50.5\%) were males and $546(26.6 \%)$ were $A P O E \varepsilon 4$ carriers. With regard to midlife physical activity, 175 participants reported not engaging, 386 reported engaging only in light intensity physical activity, 945 reported up to moderate intensity physical activity, and 554 reported up to vigorous intensity physical activity. With regard to late-life physical 
Table 1

Demographics of the study sample at baseline

\begin{tabular}{|c|c|c|c|c|c|c|}
\hline & \multicolumn{6}{|c|}{ Midlife physical activity } \\
\hline & None $(\mathrm{N}=175)$ & Light $(\mathrm{N}=386)$ & Moderate $(\mathrm{N}=945)$ & Vigorous $(\mathrm{N}=554)$ & Total $(\mathrm{N}=2,060)$ & $p$ \\
\hline Male sex, $\mathrm{N}(\%)$ & $95(54.3)$ & $153(39.6)$ & $418(44.2)$ & $374(67.5)$ & $1040(50.5)$ & $<0.01^{2}$ \\
\hline Age $(y)$ & $79.6(6.0)$ & $78.8(5.4)$ & $78.8(5.2)$ & $78.4(5.2)$ & $78.8(5.3)$ & $0.06^{1}$ \\
\hline Education (y) & $13.5(2.9)$ & $13.9(2.7)$ & $14.2(2.7)$ & $14.7(3.0)$ & $14.2(2.8)$ & $<0.01^{1}$ \\
\hline$A P O E \& 4$ carrier, $\mathrm{N}(\%)$ & $50(28.7)^{1}$ & $107(27.8)^{1}$ & $250(26.6)^{5}$ & $139(25.2)^{3}$ & $546(26.6)^{10}$ & $0.75^{2}$ \\
\hline Charlson index & $3.6(3.1)$ & $3.7(3.1)$ & $3.5(3.2)$ & $3.4(3.0)$ & $3.5(3.1)$ & $0.66^{1}$ \\
\hline $\operatorname{BMI}\left(\mathrm{kg} / \mathrm{m}^{2}\right)$ & $28.7(5.6)^{4}$ & $28.5(5.5)^{2}$ & $27.8(4.9)^{8}$ & $27.5(4.4)^{4}$ & $27.9(5.0)^{18}$ & $<0.01^{1}$ \\
\hline Follow-up time (y) & $5.4(2.7)$ & $5.7(2.8)$ & $5.8(2.8)$ & $6.1(2.9)$ & $5.8(2.8)$ & \\
\hline z-score memory & $-0.12(0.93)^{3}$ & $-0.00(1.01)^{5}$ & $0.07(1.01)^{12}$ & $-0.07(1.00)^{10}$ & $0.00(1.00)^{30}$ & \\
\hline z-score language & $-0.15(0.98)^{6}$ & $0.05(1.06)^{20}$ & $0.02(1.00)^{33}$ & $-0.01(0.97)^{14}$ & $0.00(1.00)^{73}$ & \\
\hline $\mathrm{z}$-score attention & $-0.20(1.08)^{11}$ & $-0.02(0.96)^{24}$ & $0.06(1.00)^{47}$ & $-0.02(0.99)^{12}$ & $0.00(1.00)^{94}$ & \\
\hline z-score visuospatial & $-0.00(0.96)^{13}$ & $-0.07(1.01)^{25}$ & $-0.00(1.00)^{49}$ & $0.05(1.01)^{12}$ & $0.00(1.00)^{99}$ & \\
\hline \multirow[t]{3}{*}{ z-score global } & $-0.13(1.00)^{16}$ & $-0.03(1.03)^{33}$ & $0.05(1.00)^{66}$ & $-0.02(0.99)^{25}$ & $0.00(1.00)^{140}$ & \\
\hline & \multicolumn{6}{|c|}{ Late-life physical activity } \\
\hline & None $(\mathrm{N}=328)$ & Light $(\mathrm{N}=616)$ & Moderate $(\mathrm{N}=906)$ & Vigorous $(\mathrm{N}=210)$ & Total $(\mathrm{N}=2,060)$ & $p$ \\
\hline Male sex, $\mathrm{N}(\%)$ & $149(45.4)$ & $284(46.1)$ & $462(51.0)$ & $145(69.0)$ & $1040(50.5)$ & $<0.01^{2}$ \\
\hline Age (y) & $80.0(5.8)$ & $79.1(5.2)$ & $78.4(5.2)$ & $77.3(4.7)$ & $78.8(5.3)$ & $<0.01^{1}$ \\
\hline Education (y) & $13.4(2.6)$ & $14.0(2.7)$ & $14.5(2.8)$ & $14.7(3.0)$ & $14.2(2.8)$ & $<0.01^{1}$ \\
\hline$A P O E \& 4$ carrier, $\mathrm{N}(\%)$ & $81(24.8)^{2}$ & $184(30.0)^{3}$ & $213(23.6)^{5}$ & $68(32.4)$ & $546(26.6)^{10}$ & $<0.01^{2}$ \\
\hline Charlson index & $4.3(3.4)$ & $3.8(3.3)$ & $3.2(2.9)$ & $3.3(3.0)$ & $3.5(3.1)$ & $<0.01^{1}$ \\
\hline $\operatorname{BMI}\left(\mathrm{kg} / \mathrm{m}^{2}\right)$ & $29.8(6.2)^{8}$ & $28.3(5.2)^{2}$ & $27.3(4.3)^{8}$ & $26.9(3.8)$ & $27.9(5.0)^{18}$ & $<0.01^{1}$ \\
\hline Follow-up time (y) & $5.1(2.7)$ & $5.6(2.9)$ & $6.1(2.8)$ & $6.2(2.9)$ & $5.8(2.8)$ & \\
\hline z-score memory & $-0.04(1.00)^{4}$ & $-0.01(1.01)^{9}$ & $0.01(0.99)^{12}$ & $0.03(1.01)^{5}$ & $0.00(1.00)^{30}$ & \\
\hline z-score language & $-0.11(0.99)^{9}$ & $-0.01(0.99)^{26}$ & $0.04(1.01)^{31}$ & $0.01(1.00)^{7}$ & $0.00(1.00)^{73}$ & \\
\hline z-score attention & $-0.27(1.06)^{18}$ & $-0.09(0.98)^{35}$ & $0.15(0.97)^{35}$ & $0.03(0.99)^{6}$ & $0.00(1.00)^{94}$ & \\
\hline z-score visuospatial & $-0.10(0.96)^{20}$ & $-0.03(1.02)^{33}$ & $0.05(1.01)^{41}$ & $0.04(0.94)^{5}$ & $0.00(1.00)^{99}$ & \\
\hline z-score global & $-0.17(1.02)^{27}$ & $-0.04(0.99)^{45}$ & $0.08(0.99)^{58}$ & $0.03(1.02)^{10}$ & $0.00(1.00)^{140}$ & \\
\hline
\end{tabular}

Data presented are mean (standard deviation) unless otherwise noted. None, non-active; Light, only light intensity physical activity at least 1-2 times/week; Moderate, moderate plus less intensity physical activity at least 1-2 times/week; Vigorous, vigorous plus less intensity physical activity at least 1-2 times/week; BMI, body mass index. $p$-values derived from ${ }^{1}$ ANOVA, ${ }^{2}$ Chi Square test; ${ }^{\mathrm{N}}$ Number of participants with missing data.

activity, 328 reported not engaging, 616 reported engaging only in light intensity physical activity, 906 reported up to moderate intensity, and 210 reported up to vigorous intensity physical activity. Mean followup time was 5.8 years, with a standard deviation (SD) of 2.8 years (Table 1). During follow-up, 451 participants progressed to MCI and 73 progressed to dementia.

As indicated by negative estimates for time (Table 2), cognitive function declined over time. Significant main effects, indicating the relationship between physical activity and cognitive function at baseline, were found for late-life moderate intensity physical activity and decreased memory as well as increased attention performance. Participants that reported engaging in light intensity physical activity in midlife had less decline in memory function over time compared to the reference group (i.e., no midlife physical activity; estimate [standard error] 0.047 [0.016], $p=0.004$ ), adjusting also for baseline age, sex, education, late-life physical activity, medical comorbidity, $A P O E \varepsilon 4$ genotype status, and whether or not the administration of the cognitive tests was the first time ever. In addition, vigorous intensity physical activity in late-life was associated with less decline over time in language (0.033 [0.015], $p=0.030)$, attention (0.032 [0.017], $p=0.050)$, and global cognitive function (0.039 [0.016], $p=0.012$; Table 2). For visual display of results, please refer to Figs. 1 (for midlife physical activity) and 2 (for late-life physical activity).

In models with sex interactions, we observed significant three-way interactions (time $\mathrm{x}$ physical activity $\mathrm{x}$ sex) for light intensity physical activity in midlife with language $(-0.071[0.030], p=0.020)$, visuospatial function $(-0.056$ [0.023], $p=0.015)$, attention $(-0.075$ [0.033], $p=0.024)$, and global cognitive function $(-0.095$ [0.031], $p=0.002)$. In addition, there was a significant interaction for vigorous intensity physical activity in midlife and global cognition $(-0.070$ [0.029], $p=0.017)$. In visual display of data using regression plots, it can be observed 


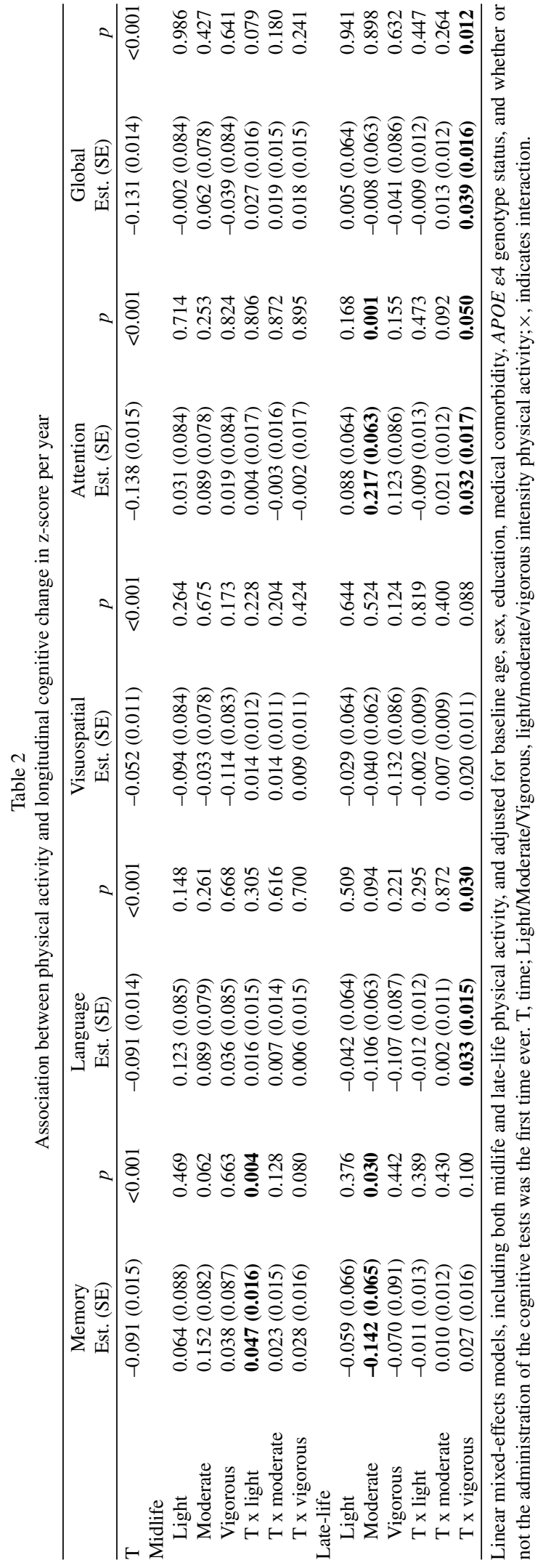

that females who do not engage in midlife physical activity as compared to females who are physically active in midlife and males regardless of physical activity, experience stronger decline in language (time $\mathrm{x}$ midlife physical activity interactions: light intensity: 0.056 [0.022], $p=0.012$; moderate intensity: 0.032 [0.021], $p=0.131$; vigorous intensity: 0.029 [0.023], $p=0.211$ ), visuospatial skills (time $\mathrm{x}$ midlife physical activity interactions: light intensity: 0.044 [0.017], $p=0.009$; moderate intensity: 0.032 [0.016], $p=0.045$; vigorous intensity: 0.034 [0.017], $p=0.053$ ), attention (time $\mathrm{x}$ midlife physical activity interactions: light intensity: 0.047 [0.024], $p=0.049$; moderate intensity: 0.031 [0.023], $p=0.176$; vigorous intensity: 0.027 [0.025], $p=0.279)$ and global cognitive function (time $\mathrm{x}$ midlife physical activity interactions: light intensity: 0.079 [0.022], $p<0.001$; moderate intensity: 0.053 [0.021], $p=0.011$; vigorous intensity: 0.056 [0.023], $p=0.014$ ) (Fig. 3; coefficients reported are for the comparison of females who do and do not engage in midlife physical activity).

There were no significant three-way interactions for time x late-life physical activity x sex (data not shown). Similarly, there were no significant threeway interactions with $A P O E \varepsilon 4$ genotype status (time x physical activity x $A P O E \varepsilon 4$; data not shown).

\section{DISCUSSION}

Engaging in physical activity was associated with less pronounced decline in various cognitive domains and global cognition. This was particularly notable for late-life vigorous intensity physical activity which was associated with less decline in language, attention and global cognition. We chose to report models that included both midlife and late-life physical activity as physical activity habits in midlife may impact those in late-life and vice versa. However, when we ran the two-way models (time x physical activity) separately for midlife and late-life, we observed even more significant associations. For midlife, engaging in light intensity physical activity was associated with less decline in memory function over time, and engaging in vigorous intensity physical activity was associated with less decline in memory and global function over time (data not shown). Similarly, engaging in late-life physical activity at vigorous intensity was associated with less decline in memory, language, attention and global cognition over time (data not shown). 

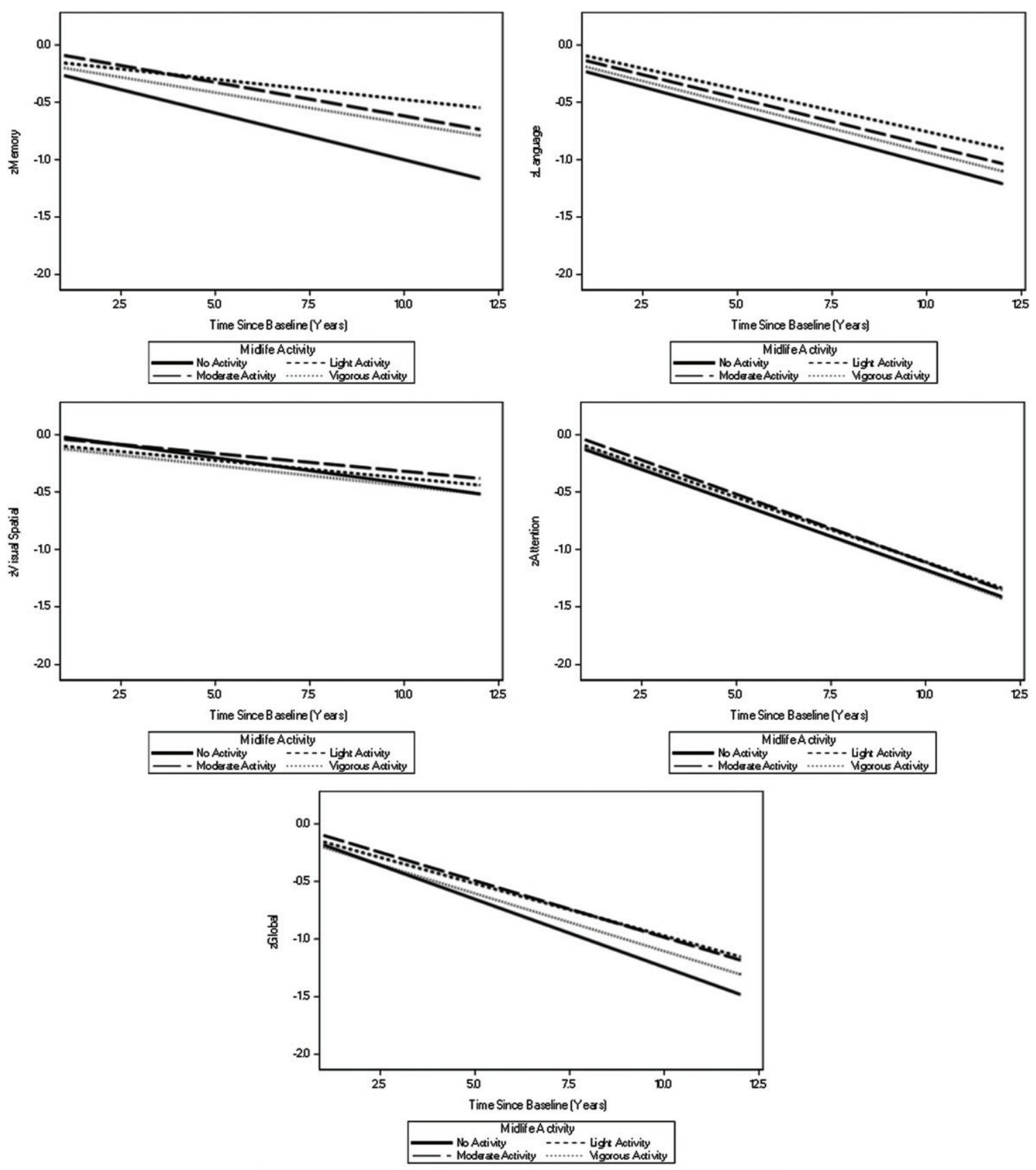

Fig. 1. Visual display of two-way interactions between time and physical activity in midlife. Models are taking into account late-life physical activity and are adjusted for baseline age, education, medical comorbidities, $A P O E \varepsilon 4$ genotype status, and whether or not the administration of the cognitive tests was the first time ever.

Furthermore, with regard to a potential sex-dependent effect, we observed that females who did not engage in midlife physical activity had significantly stronger decline in cognitive function over time as compared to other groups. These results are in line with previous research that found effects of long-term physical activity on cognitive decline in women but not in men [14, 45]. Nevertheless, studies also reported that the associations between physical activity and cognitive performance were more pronounced among males [3, 15]. Therefore, the potential impact of sex on the associations of midlife or late-life physical activity with cognitive function still remains unclear $[9,46]$. Possible explanations 

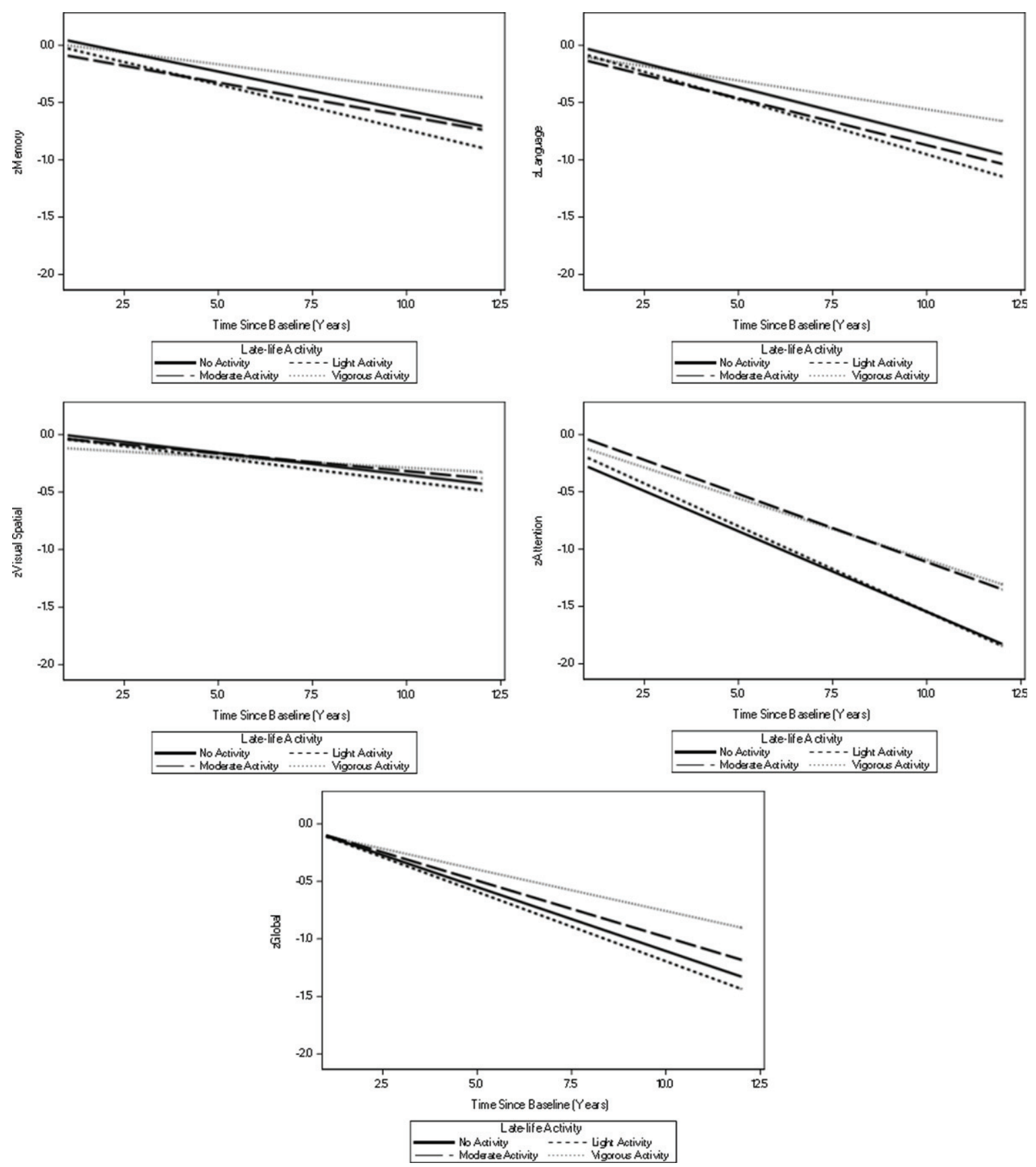

Fig. 2. Visual display of two-way interactions between time and physical activity in late-life. Models are taking into account midlife physical activity and are adjusted for baseline age, education, medical comorbidities, APOE $\varepsilon 4$ genotype status, and whether or not the administration of the cognitive tests was the first time ever.

for differences between males and females might be different physical activity patterns in men and women [9] or women may experience aging related decline in certain hormones [10].

In addition, the sex-specific three-way interactions observed between midlife physical activity and lan- guage, visuospatial function, attention and global cognition were only significant for light intensity but not moderate or vigorous intensity physical activity (except for vigorous intensity physical activity and global cognition). These findings may argue against a dose-response effect of physical activity. Previous 

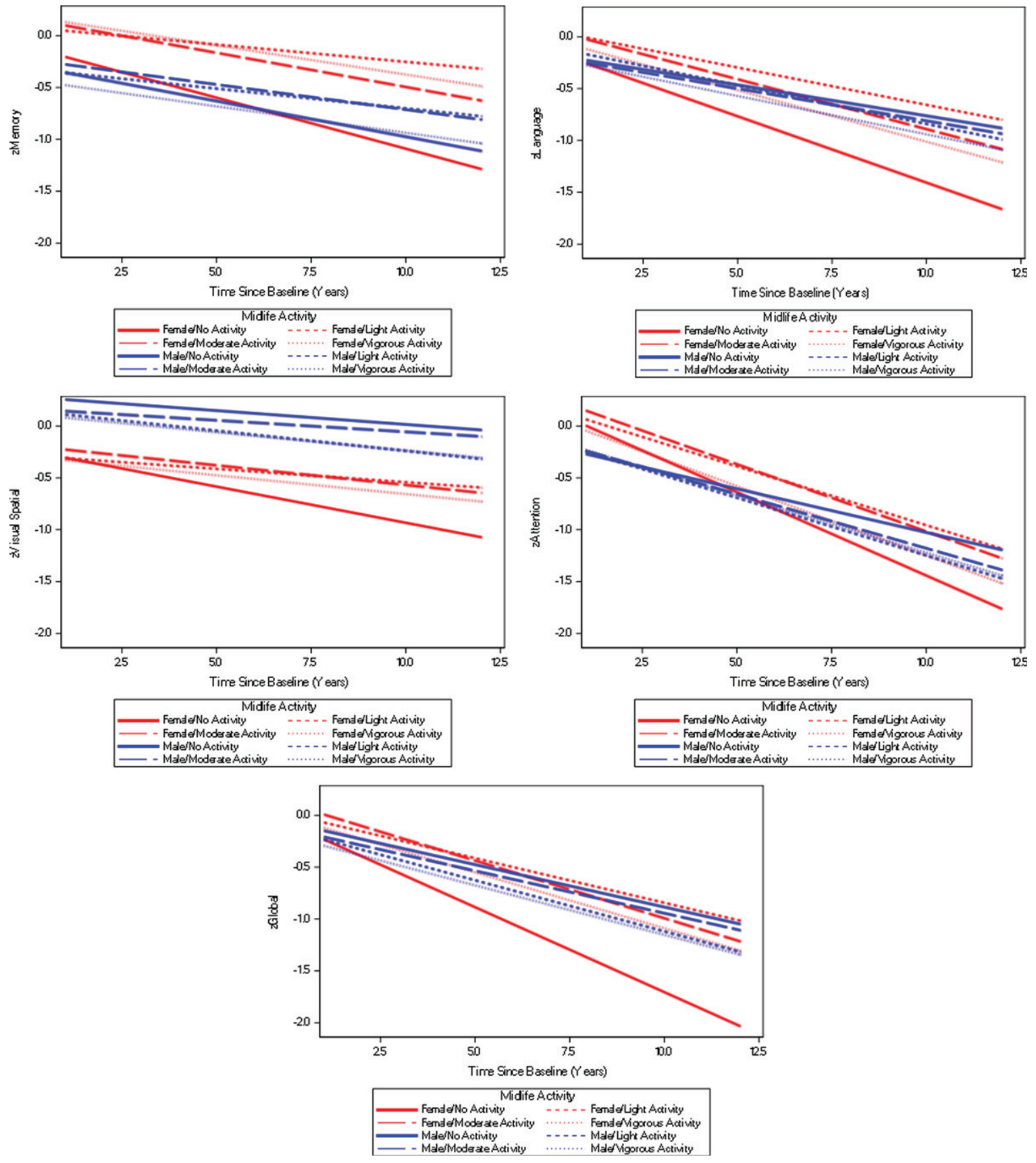

Fig. 3. Visual display of three-way interactions between time, physical activity in midlife and sex. Models are taking into account late-life physical activity and are adjusted for baseline age, education, medical comorbidities, APOE $\varepsilon 4$ genotype status, and whether or not the administration of the cognitive tests was the first time ever.

work has yielded mixed results on a potential doseresponse relationship between physical activity and cognitive function in older adults [47, 48]. Also, we only observed sex-specific interactions for midlife but not late-life physical activity, indicating that engagement in physical activity in midlife but not late-life may be associated with cognitive trajectories when taking into account biological sex. In line with this, Canadian researchers recently hypothesized that midlife is a critical time window to promote brain health and potentially prevent or delay dementia through physical activity engagement; and that 
this may be particularly true for females who experience various hormonal and neuroendocrine changes related to menopause during midlife and may thus exit this period of the lifespan at greater risk for cognitive impairment [17]. This is also supported by our observation that females who were physically inactive in midlife experienced greater cognitive decline; and more research is needed to explore this potential sex-specific effect on the association between physical activity engagement and cognitive trajectories during different times of the adult lifespan.

Interestingly, we did not observe any significant effects in regression models including time $\mathrm{x}$ physical activity x $A P O E \varepsilon 4$ interactions, indicating that the association between physical activity and less decline in cognitive function may not differ by $A P O E$ $\varepsilon 4$ genotype status. Previous research has provided preliminary evidence that the association between physical activity and cognitive decline may differ between $A P O E \& 4$ carriers and non-carriers [1, 18-21]. Thus, more research, particularly using longitudinal study designs is needed to clarify these conflicting findings.

We did not investigate mechanisms of action that may mediate a beneficial impact of physical activity on less decline in cognitive function in older adults. However, based on the literature we would like to propose biologically plausible explanations. For example, it has been postulated that reduced levels of brain-derived neurotrophic factor (BDNF), insulin-like growth factor-I (IGF-I), and vascular endothelial growth factor (VEGF) can be indicators for early cognitive decline; in turn, physical activity is known to increase some of these trophic factors [49], thereby leading to increased cell growth and neuronal function [50]. Some studies have shown that the relationship between physical activity and cognition might be mediated by BDNF depending on Val/Met carrier status [51], and that these associations may additionally be modified by sex [52]. Another potential explanation for an association between physical activity and less decline in cognitive function may be that engaging in physical activity is a marker for a healthy lifestyle in general, i.e., persons that are physically active on a regular basis may show the same type of discipline with regard to other health promoting behaviors such as following a healthy diet or having regular medical check-ups. Of note, it is also possible that reverse causality may account for our findings, i.e., persons who are in the incipient stages of cognitive impairment and are likely to experience future cognitive decline, may engage in physical activity to a lesser extent than participants who are not in incipient stages of cognitive impairment and may thus experience no or only very subtle decline in cognitive function over time. This may particularly account for our observations on late-life physical activity and its associations with cognitive trajectories.

The strengths of our current investigation are the population-based, longitudinal study design, available information about $A P O E \& 4$ carrier status of participants and a rigorous assessment of cognitive change over time using repeated, validated neuropsychological testing. Limitations pertain to the observational nature of our study, i.e., we cannot draw any conclusion about the cause-effect relationship between the presumed predictor (physical activity) and the outcome of interest (change in cognitive function over time). Another major limitation is the assessment of engagement in physical activity through a self-reported questionnaire which may be prone to recall bias, particularly with regard to physical activity carried out in midlife. Also, the questionnaire did not take into account potential seasonal effects or duration of physical activities; and we were also not able to compare effects between different types of activities that may have additional effects on cognitive function (i.e., tennis or dancing that have a social interaction component). However, the questionnaire was derived from two validated instruments, has shown moderate to good internal consistency, and test-retest correlation coefficients range between 0.33 for vigorous intensity activity and 0.50 for moderate intensity activity [40]. Furthermore, we were interested not only in late-life but also midlife engagement in physical activity in our study participants, and this information could only be captured by a self-reported questionnaire. It must be noted though that validated tools to objectively measure physical activity such as accelerometers are now available and are frequently used in cross-sectional studies investigating the relationship between physical activity and cognition [53-55]. As of today, only few longitudinal studies have been published that used these devices in the context of cognitive aging [56], even though the use of accelerometers may yield more detailed information about physical activity and its longitudinal association with cognitive function. In addition, based on the classification of physically active persons in this analysis, 945 participants (46\%) reported up to moderate intensity midlife physical activity, and $554(27 \%)$ reported up to vigorous intensity midlife physical activity. With regard to late-life physical 
activity, 906 (44\%) reported up to moderate intensity, and $210(10 \%)$ reported up to vigorous intensity physical activity. These may be higher rates compared to published statistics or previous publications, and may impact generalizability of study findings. Finally, we did not examine how changes in physical activity behavior may be related to cognitive decline. As evident from Table 1, participants are less physically active in late-life as compared to midlife. Also, participants with higher levels of physical activity may be more prone to a decline in physical activity level over time. Future research should focus on whether these people initially have a higher cognitive level, but experience a stronger cognitive decline due to aging and reduction in physical activity level. It would also be important to examine other novel types of physical activity such as whole body vibration training which has shown promising preliminary effects on various outcomes in older adults with cognitive impairment $[57,58]$.

In conclusion, our study demonstrates a potentially beneficial effect of physical activity on more preserved cognitive function over time. More research is needed to examine the longitudinal associations between physical activity and cognitive function in older adults.

\section{ACKNOWLEDGMENTS}

Support for this research was provided by NIH grants: National Institute on Aging (R01 AG057708; U01 AG006786; P50 AG016574; R01 AG034676), and National Institute of Mental Health (K01 MH068351). This project was also supported by the Robert Wood Johnson Foundation, the Robert H. and Clarice Smith and Abigail Van Buren Alzheimer's Disease Research Program, the GHR Foundation, the Mayo Foundation for Medical Education and Research, the Edli Foundation and the Arizona Alzheimer's Consortium.

Authors' disclosures available online (https:// www.j-alz.com/manuscript-disclosures/20-0959r2).

\section{REFERENCES}

[1] Tan ZS, Spartano NL, Beiser AS, DeCarli C, Auerbach SH, Vasan RS, Seshadri S (2017) Physical activity, brain volume, and dementia risk: The Framingham Study. J Gerontol A Biol Sci Med Sci 72, 789-795.

[2] Kishimoto H, Ohara T, Hata J, Ninomiya T, Yoshida D, Mukai N, Nagata M, Ikeda F, Fukuhara M, Kumagai S, Kanba S, Kitazono T, Kiyohara Y (2016) The long-term association between physical activity and risk of dementia in the community: The Hisayama Study. Eur J Epidemiol 31, 267-274.

[3] Tolppanen AM, Solomon A, Kulmala J, Kareholt I, Ngandu T, Rusanen M, Laatikainen T, Soininen H, Kivipelto M (2015) Leisure-time physical activity from mid- to late life, body mass index, and risk of dementia. Alzheimers Dement 11, 434-443 e436.

[4] Krell-Roesch J, Pink A, Roberts RO, Stokin GB, Mielke MM, Spangehl KA, Bartley MM, Knopman DS, Christianson TJ, Petersen RC, Geda YE (2016) Timing of physical activity, apolipoprotein E epsilon4 genotype, and risk of incident mild cognitive impairment. J Am Geriatr Soc 64, 2479-2486.

[5] Gaertner B, Buttery AK, Finger JD, Wolfsgruber S, Wagner M, Busch MA (2018) Physical exercise and cognitive function across the life span: Results of a nationwide population-based study. J Sci Med Sport 21, 489-494.

[6] Stubbs B, Chen LJ, Chang CY, Sun WJ, Ku PW (2017) Accelerometer-assessed light physical activity is protective of future cognitive ability: A longitudinal study among community dwelling older adults. Exp Gerontol 91, 104-109.

[7] Willey JZ, Gardener H, Caunca MR, Moon YP, Dong C, Cheung YK, Sacco RL, Elkind MS, Wright CB (2016) Leisure-time physical activity associates with cognitive decline: The Northern Manhattan Study. Neurology 86, 1897-1903.

[8] Reas ET, Laughlin GA, Bergstrom J, Kritz-Silverstein D, McEvoy LK (2019) Physical activity and trajectories of cognitive change in community-dwelling older adults: The Rancho Bernardo Study. J Alzheimers Dis 71, 109-118.

[9] Reas ET, Laughlin GA, Bergstrom J, Kritz-Silverstein D, Richard EL, Barrett-Connor E, McEvoy LK (2019) Lifetime physical activity and late-life cognitive function: The Rancho Bernardo study. Age Ageing 48, 241-246.

[10] Gill SJ, Friedenreich CM, Sajobi TT, Longman RS, Drogos LL, Davenport MH, Tyndall AV, Eskes GA, Hogan DB, Hill MD, Parboosingh JS, Wilson BJ, Poulin MJ (2015) Association between lifetime physical activity and cognitive functioning in middle-aged and older community dwelling adults: Results from the brain in motion study. $\mathrm{J}$ Int Neuropsychol Soc 21, 816-830.

[11] Sabia S, Dugravot A, Dartigues JF, Abell J, Elbaz A, Kivimaki M, Singh-Manoux A (2017) Physical activity, cognitive decline, and risk of dementia: 28 year follow-up of Whitehall II cohort study. BMJ 357, j2709.

[12] Zhou XL, Wang LN, Wang J, Zhou L, Shen XH (2020) Effects of exercise interventions for specific cognitive domains in old adults with mild cognitive impairment: A meta-analysis and subgroup analysis of randomized controlled trials. Medicine (Baltimore) 99, e20105.

[13] Lamb SE, Sheehan B, Atherton N, Nichols V, Collins H, Mistry D, Dosanjh S, Slowther AM, Khan I, Petrou S, Lall R, Investigators DT (2018) Dementia And Physical Activity (DAPA) trial of moderate to high intensity exercise training for people with dementia: Randomised controlled trial. BMJ 361, k1675.

[14] Barha CK, Davis JC, Falck RS, Nagamatsu LS, LiuAmbrose T (2017) Sex differences in exercise efficacy to improve cognition: A systematic review and meta-analysis of randomized controlled trials in older humans. Front Neuroendocrinol 46, 71-85.

[15] Stern Y, Lee S, Predovan D, Sloan RP (2019) Sex moderates the effect of aerobic exercise on some aspects of cognition in cognitively intact younger and middle-age adults. $J$ Clin Med 8, 886 
[16] Fallah N, Mitnitski A, Middleton L, Rockwood K (2009) Modeling the impact of sex on how exercise is associated with cognitive changes and death in older Canadians. Neuroepidemiology $33,47-54$.

[17] Barha CK, Liu-Ambrose T (2020) Sex differences in exercise efficacy: Is midlife a critical window for promoting healthy cognitive aging? FASEB J, doi:10.1096/fj. 202000857R.

[18] Etnier JL, Karper WB, Labban JD, Piepmeier AT, Shih CH, Dudley WN, Henrich VC, Wideman L (2018) The Physical Activity and Alzheimer's Disease (PAAD) study: Cognitive outcomes. Ann Behav Med 52, 175-185.

[19] Pizzie R, Hindman H, Roe CM, Head D, Grant E, Morris JC, Hassenstab JJ (2014) Physical activity and cognitive trajectories in cognitively normal adults: The adult children study. Alzheimer Dis Assoc Disord 28, 50-57.

[20] Schuit AJ, Feskens EJ, Launer LJ, Kromhout D (2001) Physical activity and cognitive decline, the role of the apolipoprotein e4 allele. Med Sci Sports Exerc 33, 772-777.

[21] Rovio S, Kareholt I, Helkala EL, Viitanen M, Winblad B, Tuomilehto J, Soininen H, Nissinen A, Kivipelto M (2005) Leisure-time physical activity at midlife and the risk of dementia and Alzheimer's disease. Lancet Neurol 4, 705-711.

[22] Corder EH, Saunders AM, Strittmatter WJ, Schmechel DE, Gaskell PC, Small GW, Roses AD, Haines JL, PericakVance MA (1993) Gene dose of apolipoprotein E type 4 allele and the risk of Alzheimer's disease in late onset families. Science 261, 921-923.

[23] Saunders AM, Strittmatter WJ, Schmechel D, GeorgeHyslop PH, Pericak-Vance MA, Joo SH, Rosi BL, Gusella JF, Crapper-MacLachlan DR, Alberts MJ, et al. (1993) Association of apolipoprotein E allele epsilon 4 with lateonset familial and sporadic Alzheimer's disease. Neurology 43, 1467-1472.

[24] de Frutos-Lucas J, Frost N, Erickson KI, Serrano JM, Maestu F, Laws SM, Brown BM (2020) Does APOE genotype moderate the relationship between physical activity, brain health and dementia risk? A systematic review. Ageing Res Rev 64, 101173.

[25] Roberts RO, Geda YE, Knopman DS, Cha RH, Pankratz VS, Boeve BF, Ivnik RJ, Tangalos EG, Petersen RC, Rocca WA (2008) The Mayo Clinic Study of Aging: Design and sampling, participation, baseline measures and sample characteristics. Neuroepidemiology 30, 58-69.

[26] Kokmen E, Smith GE, Petersen RC, Tangalos E, Ivnik RC (1991) The Short Test of Mental Status: Correlations with standardized psychometric testing. Arch Neurol 48, 725-728.

[27] Morris JC (1993) The Clinical Dementia Rating (CDR): Current version and scoring rules. Neurology 43, 24122414.

[28] Rey A (1964) L'examen clinique en psychologie, Presses Universitaires de France, Paris.

[29] Wechsler D (1987) Wechsler Memory Scale-Revised, The Psychological Corporation, New York.

[30] Kaplan E, Goodglass H, Weintraub S (2001) Boston Naming Test, Lippincott Williams \& Wilkins, Philadelphia.

[31] Lucas JA, Ivnik RJ, Smith GE, Bohac DL, Tangalos EG, Graff-Radford NR, Petersen RC (1998) Mayo's Older Americans Normative Studies: Category fluency norms. $J$ Clin Exp Neuropsychol 20, 194-200.

[32] Wechsler D (1981) Wechsler Adult Intelligence ScaleRevised, Psychological Corporation, New York.
[33] Reitan RM (1958) Validity of the Trail Making Test as an indicator of organic brain damage. Percept Mot Skills 8, 271-276.

[34] Ivnik RJ, Malec JF, Smith GE, Tangalos EG, Petersen RC, Kokmen E, Kurland LT (1992) Mayo's Older Americans Normative Studies: WAIS-R norms for ages 56 to 97 . Clin Neuropsychol 6, 1-30.

[35] Ivnik RJ, Malec JF, Smith GE, Tangalos EG, Petersen RC, Kokmen E, Kurland LT (1992) Mayo's Older Americans Normative Studies: WMS-R norms for ages 56 to 94 . Clin Neuropsychol 6, 49-82.

[36] Ivnik RJ, Malec JF, Smith GE, Tangalos EG, Petersen RC, Kokmen E, Kurland LT (1992) Mayo's Older Americans Normative Studies: Updated AVLT norms for ages 56 to 97. Clin Neuropsychol 6, 83-104.

[37] Malec JF, Ivnik RJ, Smith GE, Tangalos EG, Petersen RC, Kokmen E, Kurland LT (1992) Mayo's Older Americans Normative Studies: Utility of corrections for age and education for the WAIS-R. Clin Neuropsychol 6, 31-47.

[38] Petersen RC (2004) Mild cognitive impairment as a diagnostic entity. J Intern Med 256, 183-194.

[39] Winblad B, Palmer K, Kivipelto M, Jelic V, Fratiglioni L, Wahlund LO, Nordberg A, Backman L, Albert M, Almkvist O, Arai H, Basun H, Blennow K, de Leon M, DeCarli C, Erkinjuntti T, Giacobini E, Graff C, Hardy J, Jack C, Jorm A, Ritchie K, van Duijn C, Visser P, Petersen RC (2004) Mild cognitive impairment-beyond controversies, towards a consensus: Report of the International Working Group on Mild Cognitive Impairment. J Intern Med 256, 240-246.

[40] Geda YE, Roberts RO, Knopman DS, Christianson TJ, Pankratz VS, Ivnik RJ, Boeve BF, Tangalos EG, Petersen RC, Rocca WA (2010) Physical exercise, aging, and mild cognitive impairment: A population-based study. Arch Neurol 67, 80-86.

[41] Folsom AR, Caspersen CJ, Taylor HL, Jacobs DR, Jr., Luepker RV, Gomez-Marin O, Gillum RF, Blackburn H (1985) Leisure time physical activity and its relationship to coronary risk factors in a population-based sample. The Minnesota Heart Survey. Am J Epidemiol 121, 570-579.

[42] National Center for Health Statistics (US), Moss AJ, Parsons VL (1986) Current estimates from the National Health Interview Survey, United States, 1985. Vital and Health Statistics, Series 10, No. 160. DHHS Pub. No. (PHS) 861588. Public Health Service, Washington, U.S. Government Printing Office.

[43] Charlson ME, Pompei P, Ales KL, MacKenzie CR (1987) A new method of classifying prognostic comorbidity in longitudinal studies: Development and validation. J Chronic Dis 40, 373-383.

[44] Hixson JE, Vernier DT (1990) Restriction isotyping of human apolipoprotein $\mathrm{E}$ by gene amplification and cleavage with HhaI. J Lipid Res 31, 545-548.

[45] Lopez-Fontana I, Castanier C, Le Scanff C, Perrot A (2018) Protective role of recent and past long-term physical activity on age-related cognitive decline: The moderating effect of sex. J Aging Phys Act 26, 353-362.

[46] Barha CK, Liu-Ambrose T (2018) Exercise and the aging brain: Considerations for sex differences. Brain Plast 4, 53-63.

[47] Sanders LMJ, Hortobagyi T, la Bastide-van Gemert S, van der Zee EA, van Heuvelen MJG (2019) Dose-response relationship between exercise and cognitive function in older adults with and without cognitive impairment: A systematic review and meta-analysis. PLoS One 14, e0210036. 
[48] Gujral S, Oberlin L (2020) Is there a dose-response relationship between exercise and cognitive function in older adults? Am J Geriatr Psychiatry, doi:10.1016/j.jagp.2020.07.016.

[49] Tsai CL, Pai MC, Ukropec J, Ukropcova B (2019) Distinctive effects of aerobic and resistance exercise modes on neurocognitive and biochemical changes in individuals with mild cognitive impairment. Curr Alzheimer Res 16, 316-332.

[50] Maass A, Duzel S, Brigadski T, Goerke M, Becke A, Sobieray U, Neumann K, Lovden M, Lindenberger U, Backman L, Braun-Dullaeus R, Ahrens D, Heinze HJ, Muller NG, Lessmann V, Sendtner M, Duzel E (2016) Relationships of peripheral IGF-1, VEGF and BDNF levels to exercise-related changes in memory, hippocampal perfusion and volumes in older adults. Neuroimage 131, 142-154.

[51] Thibeau S, McFall GP, Wiebe SA, Anstey KJ, Dixon RA (2016) Genetic factors moderate everyday physical activity effects on executive functions in aging: Evidence from the Victoria Longitudinal Study. Neuropsychology 30, 6-17.

[52] Watts A, Andrews SJ, Anstey KJ (2018) Sex differences in the impact of BDNF genotype on the longitudinal relationship between physical activity and cognitive performance. Gerontology 64, 361-372.

[53] Iso-Markku P, Waller K, Vuoksimaa E, Vaha-Ypya H, Lindgren N, Heikkila K, Sievanen H, Rinne J, Kaprio J, Kujala UM (2018) Objectively measured physical activity profile and cognition in Finnish elderly twins. Alzheimers Dement (N Y) 4, 263-271.
[54] Zhu W, Howard VJ, Wadley VG, Hutto B, Blair SN, Vena JE, Colabianchi N, Rhodes D, Hooker SP (2015) Association between objectively measured physical activity and cognitive function in older adults-The Reasons for Geographic and Racial Differences in Stroke Study. J Am Geriatr Soc 63, 2447-2454.

[55] Kerr J, Marshall SJ, Patterson RE, Marinac CR, Natarajan L, Rosenberg D, Wasilenko K, Crist K (2013) Objectively measured physical activity is related to cognitive function in older adults. J Am Geriatr Soc 61, 1927-1931.

[56] Zhu W, Wadley VG, Howard VJ, Hutto B, Blair SN, Hooker SP (2017) Objectively measured physical activity and cognitive function in older adults. Med Sci Sports Exerc 49, 47-53.

[57] Lam FMH, Liao LR, Kwok TCY, Pang MYC (2018) Effects of adding whole-body vibration to routine day activity program on physical functioning in elderly with mild or moderate dementia: A randomized controlled trial. Int $J$ Geriatr Psychiatry 33, 21-30.

[58] Kim KH, Lee HB (2018) The effects of whole body vibration exercise intervention on electroencephalogram activation and cognitive function in women with senile dementia. J Exerc Rehabil 14, 586-591. 